\begin{tabular}{r|l|l|l}
$\begin{array}{c}\text { Case Reports in } \\
\text { Gastroenterology }\end{array}$ & $\begin{array}{l}\text { Case Rep Gastroenterol 2010;4:469-475 } \\
\text { DOl: 10.1159/000321992 }\end{array}$ & $\begin{array}{l}\text { Published online: } \\
\text { October 26, 2010 }\end{array}$ & $\begin{array}{l}\text { O 2010 S. Karger AG, Basel } \\
\text { ISSN 1662-0631 } \\
\text { www.karger.com/crg }\end{array}$ \\
\hline
\end{tabular}

\title{
Autoimmune Hepatitis and Celiac Disease: Case Report Showing an Entero-Hepatic Link
}

\author{
Francesco Tovoli Roberto De Giorgio Giacomo Caio \\ Valentina Grasso Chiara Frisoni Mauro Serra \\ Carla Caputo Vincenzo Stanghellini Luigi Bolondi \\ Roberto Corinaldesi Umberto Volta
}

Department of Clinical Medicine and Department of Digestive Diseases and Internal Medicine, Sant'Orsola-Malpighi Hospital, Università Alma Mater

Studiorum di Bologna, Bologna, Italy

\section{Key Words}

Celiac disease $\cdot$ Autoimmune hepatitis $\cdot$ Hypertransaminasemia $\cdot \gamma$-Globulins $\cdot$ Anti-dsDNA antibodies

\begin{abstract}
Celiac disease is an autoimmune disorder primarily targeting the small bowel, although extraintestinal extensions have been reported. The autoimmune processes can affect the liver with manifestations such as primary biliary cirrhosis and autoimmune hepatitis. We describe a 61-year-old woman with celiac disease and an increased levels of aminotransferases. The persistence of increased levels of aminotransferases after 1 year of gluten-free diet and the positivity for an anti-nuclear and anti-double-strand DNA antibodies led to a misdiagnosis of systemic lupus erythematosus-related hepatitis. Based on these findings the patient was placed on steroids, which after a few months were stopped because of the onset of diabetes mellitus. Soon after steroid withdrawal, the patient had a marked increase in aminotransferases and $\gamma$-globulins, and a liver biopsy revealed chronic active hepatitis. A course of three months of steroids and azathioprine normalized both biochemical and clinical parameters. Currently the patient is symptom-free and doing well. In conclusion, a hypertransaminasemia persisting after a gluten-free diet should be interpreted as a sign of coexisting autoimmune liver disease. Any autoantibody positivity (in this case to ANA and anti-dsDNA) should be carefully considered in order to avoid misdiagnosis delaying appropriate clinical management.
\end{abstract}




\begin{tabular}{r|l|l|l}
$\begin{array}{r}\text { Case Reports in } \\
\text { Gastruanteriology }\end{array}$ & $\begin{array}{l}\text { Case Rep Gastroenterol 2010;4:469-475 } \\
\text { DOI: 10.1159/000321992 }\end{array}$ & $\begin{array}{l}\text { Published online: } \\
\text { October 26, 2010 }\end{array}$ & $\begin{array}{l}\text { O 2010 S. Karger AG, Basel } \\
\text { ISSN 1662-0631 } \\
\text { www.karger.com/crg }\end{array}$ \\
\hline
\end{tabular}

\section{Introduction}

Celiac disease $(\mathrm{CD})$ is an autoimmune disorder triggered by the ingestion of wheat gliadins and/or other cereal prolamins in patients with genetic predisposition [1]. Although the small bowel is the main target of the disease with a resultant variable degree of malabsorption, growing evidence shows that $\mathrm{CD}$ is a systemic disorder that may affect several other organs outside the gut, i.e. the nervous system, thyroid, pancreas, connective tissue, bone, heart, skin, and liver [2]. The occurrence of liver impairment in CD is well established and can be regarded as one of the manifold extraintestinal presentations of gluten-sensitive enteropathy [3]. In this context, different patterns of liver injury can be observed in CD patients, including a close association with autoimmune liver disorders such as primary biliary cirrhosis, autoimmnune hepatitis and primary sclerosing cholangitis $[4,5]$. Here we report the case of a CD patient with autoimmune hepatitis (AIH) whose liver involvement was initially attributed to systemic lupus erythematosus (SLE). This misdiagnosis delayed the definition of celiac-related AIH and appropriate management.

\section{Case Report}

A 61-year-old woman was evaluated for an unclear elevation of liver aminotransferases (both AST and ALT about 3 times above the normal limit) associated with a hyper- $\gamma$-globulinemia unrelated to hepatotropic viruses and toxic causes. Her past medical history was mainly characterized by two spontaneous miscarriages, iron deficiency anemia, osteopenia and alternating bowel habit. Due to the persistence of gastrointestinal symptoms, she underwent serological tests for CD that resulted positive for anti-endomysial antibodies (IgA EmA, 1:160). Duodenal biopsy revealed severe villous atrophy (3c according to the Marsh-Oberhüber classification). HLA typing revealed DQ2 (DQA $1^{*} 0501$, DQB1*0201) and DQ8 (DQB1*0302) heterodimer positivity. A diagnosis of CD was established and the patient was placed on a gluten-free diet (GFD) with remission of symptoms within about six months. After one year, routine serological tests still revealed an increase in AST and ALT aminotransferases (about 3 times above the normal limit). Other findings included a slight increase in bilirubin ( $1.5 \mathrm{mg} / \mathrm{dl})$ and low levels of platelets $\left(95,000 / \mathrm{mm}^{3}\right)$. Autoantibody profile was characterized by positive anti-nuclear antibody (ANA +++, homogenous pattern) and anti-double-strand DNA (anti-dsDNA 1:160). A diagnosis of SLE with lupus-related hepatitis was made and steroidal therapy was started (prednisone $25 \mathrm{mg} /$ day). Owing to the onset of steroid-induced diabetes mellitus, prednisone treatment was stopped. Soon after steroid withdrawal, the patient was referred to our unit. Laboratory tests showed a marked increase in AST and ALT aminotransferases ( 35 times above the normal limit), hyperbilirubinemia $4.05 \mathrm{mg} / \mathrm{dl}$ and high levels of total proteins $(9.1 \mathrm{~g} / \mathrm{dl})$, albumin $(3.8 \mathrm{~g} / \mathrm{dl}), \gamma$-globulins (3.6 g/dl), IgG (2,680 mg/dl), IgA (489 mg/dl) and IgM (273 mg/dl). The autoimmune profile confirmed a strong positivity of ANA (+++, with homogenous pattern), anti-smooth muscle antibodies (SMA, ++ with vessel pattern), anti-dsDNA (1:320), while CD-related autoantibodies were negative, showing a good compliance to GFD. Ultrasound-Doppler examination revealed an enlarged liver with irregular borders and coarse echo pattern along with signs of portal hypertension. A liver biopsy showed chronic

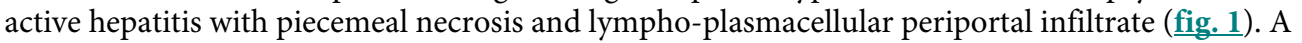
diagnosis of $\mathrm{AIH}$ associated with $\mathrm{CD}$ was made and the patient was treated with methylprednisolone $(16 \mathrm{mg} /$ day $)$ and azathioprine $(2 \mathrm{mg} / \mathrm{kg}=100 \mathrm{mg} /$ day $)$. At 18 -month follow-up, the patient was doing well with an almost complete normalization of aminotransferases (ig. 2$), \gamma$-globulins (ig. 3$)$ and bilirubin. Methylprednisolone and azathioprine have been tapered down to the current dose of $4 \mathrm{mg} /$ day and $50 \mathrm{mg} /$ day, respectively. The patient gave her informed consent to the publication of this case report. 


\begin{tabular}{r|l|l|l} 
Case Reports in & $\begin{array}{l}\text { Case Rep Gastroenterol 2010;4:469-475 } \\
\text { DOl: 10.1159/000321992 }\end{array}$ & $\begin{array}{l}\text { Published online: } \\
\text { October 26, 2010 }\end{array}$ & $\begin{array}{l}\text { ISSN 1662-0631 } \\
\text { ISS } \\
\text { www.karger.com/crg }\end{array}$ \\
\hline
\end{tabular}

\section{Discussion}

The spectrum of liver abnormalities in the context of CD is particularly wide, however, two main forms of liver damage, i.e. cryptogenic and autoimmune, appear to be strictly associated with gluten-sensitive enteropathy [3]. Hypertransaminasemia has been reported in up to $47 \%$ of adults with a classical presentation of CD at the time of diagnosis [6]. Conversely, $\mathrm{CD}$ is present in about $9 \%$ of patients with chronic unexplained hypertransaminasemia and liver blood test abnormalities may also be the sole presentation of atypical CD [7]. In patients with untreated CD, cryptogenic liver disorder, also referred to as 'celiac hepatitis', is usually characterized by a mild increase in aminotransferase levels with normal values of bilirubin and $\gamma$-GT $[8,9]$. A GFD leads to normalization of serum aminotransferases in almost all patients with CD within one year of good adherence to the diet [10]. In patients with missed or late diagnosis, CD may be also associated with severe forms of liver disease, including advanced cirrhosis which can require liver transplantation [11]. Sometimes the identification of CD in these patients can significantly improve liver function, leading to disappearance of ascites and jaundice, thereby avoiding liver transplantation [12].

Another clinically relevant association, which pertains to the present case report, is that between $\mathrm{CD}$ and autoimmune liver disorders. In this context, primary biliary cirrhosis is the most frequent liver disease found in patients with $\mathrm{CD}[13,14]$. In this case report, we describe the association between $\mathrm{CD}$ and type $1 \mathrm{AIH}$. Such an association has been demonstrated by two antibody screening studies for $\mathrm{CD}$ in large series of patients with AIH $[4,5]$. One of these studies included the largest series of patients with AIH screened for CD with serology [4]. Based on serological response, the CD prevalence was $4.4 \%$ ( $8.3 \%$ in type $2 \mathrm{AIH}, 3.8 \%$ in type $1 \mathrm{AIH}$ ), whereas, taking into account only cases who underwent duodenal biopsy, CD prevalence was $2.8 \%$.

In the patient described here, GFD improved the symptoms attributable to CD due to normalization of the small intestinal mucosa, but it did not normalize aminotransferases. This finding along with the positivity for ANA (homogeneous pattern) and anti-dsDNA antibodies led to a misdiagnosis of SLE-related hepatitis. Based on the lack of clinical signs and symptoms suggesting SLE, the presence of these two autoantibodies should have been considered a clue to type 1 AIH [15] whose diagnosis could be supported by the detection of high-titer circulating SMA (vessel pattern). In addition, another relevant clinical feature of our patient suggesting type $1 \mathrm{AIH}$ was the rebound of aminotransferase levels after steroid withdrawal. Finally, the histological pattern was consistent with AIH, showing chronic active hepatitis with piecemeal necrosis.

The present case was a diagnostic challenge as it dealt with the interesting and not uncommon association between $\mathrm{CD}$ and liver disease. Accordingly, we propose the following conclusions: (a) Hypertransaminasemia can be secondary to CD-related hepatitis; it can as well be a clue for underlying coexisting autoimmune liver disease. For these reasons liver enzyme levels should be checked routinely in all patients with $\mathrm{CD}$ at diagnosis. (b) Once it has been established that hypertransaminasemia is of CD origin, liver enzymes should be controlled after 6-12 months after the beginning of a GFD. Persistently elevated levels of aminotransferases (once a poor compliance to the diet has been excluded) should be regarded as a sign of coexisting autoimmune liver disease other than celiac hepatitis, thus the etiology of liver disorder must be re-assessed. (c) The positivity of ANA and anti-dsDNA antibodies should not be regarded as uniquely 


\begin{tabular}{r|l|l|l}
$\begin{array}{r}\text { Case Reports in } \\
\text { Gastruanteriology }\end{array}$ & $\begin{array}{l}\text { Case Rep Gastroenterol 2010;4:469-475 } \\
\text { DOI: 10.1159/000321992 }\end{array}$ & $\begin{array}{l}\text { Published online: } \\
\text { October 26, 2010 }\end{array}$ & $\begin{array}{l}\text { O 2010 S. Karger AG, Basel } \\
\text { ISSN 1662-0631 } \\
\text { www.karger.com/crg }\end{array}$ \\
\hline
\end{tabular}

diagnostic for SLE, but these autoantibodies along with SMA suggest an underlying type 1 $\mathrm{AIH}$, particularly in the presence of very high levels of aminotransferases and $\gamma$-globulin.

This case helps to shed light on the appropriateness and accurate interpretation of laboratory and diagnostic tests to establish a diagnosis of CD-related liver disease.

\section{Disclosure Statement}

The authors declare no conflict of interest.

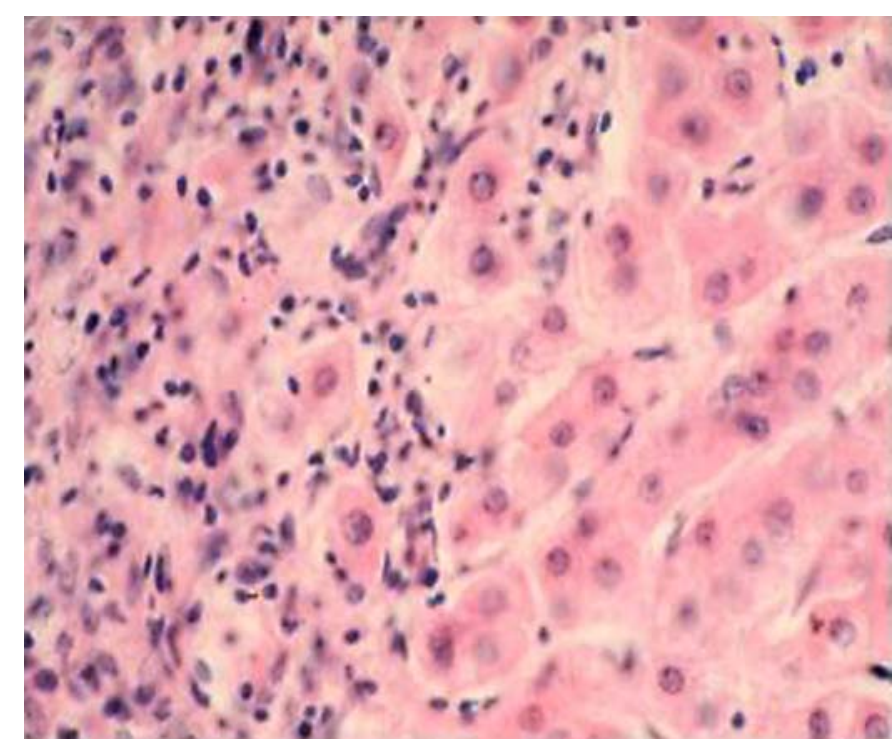

Fig. 1. Representative picture of liver biopsy of the reported case taken upon withdrawal of steroid treatment in association with a flare-up of aminotransferases and $\gamma$-globulins. Note the chronic active hepatitis characterized by piecemeal necrosis and lympho-plasmacellular infiltrate. H\&E staining, original magnification 40x. 


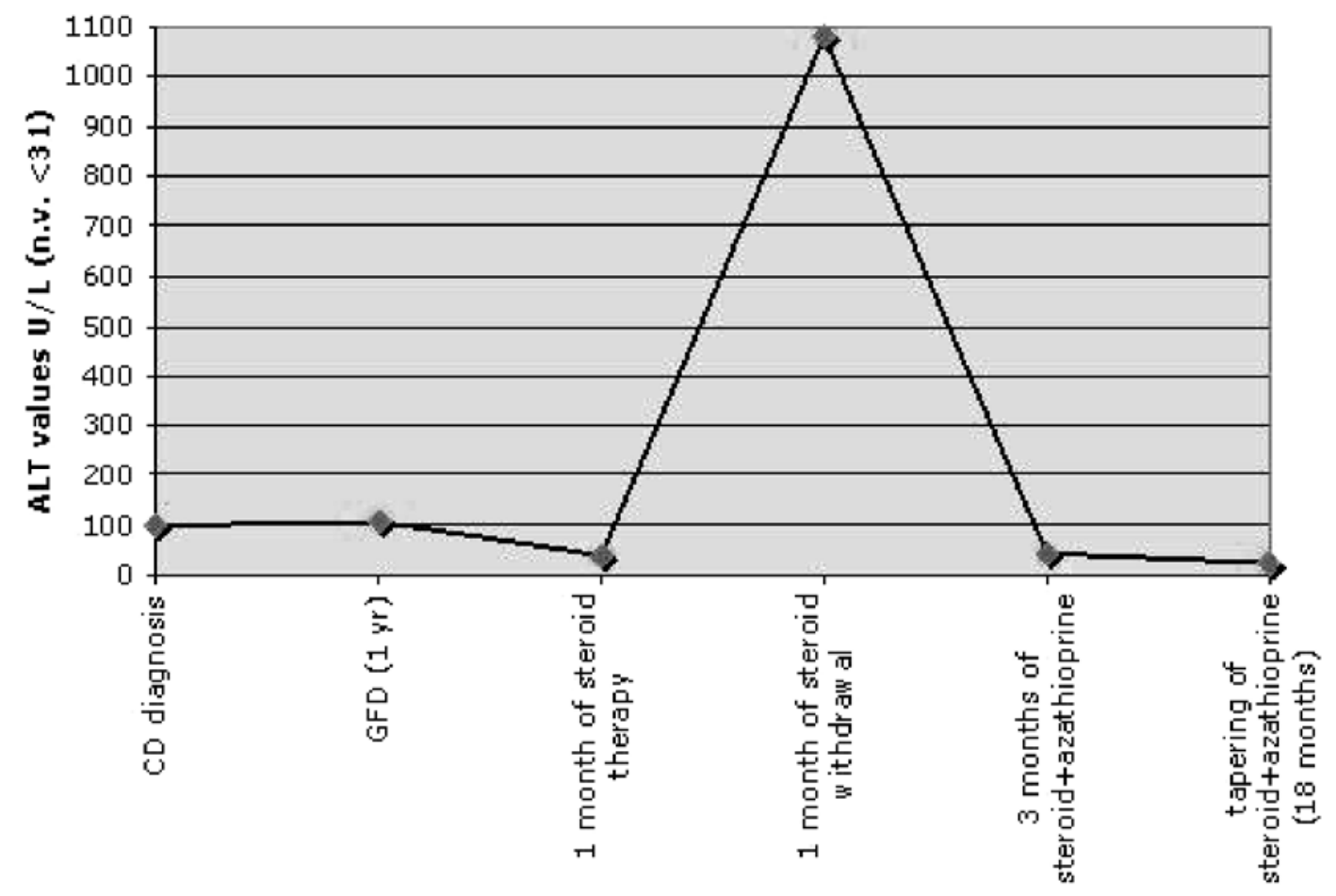

time

Fig. 2. Diagram showing ALT aminotransferases levels over time. At CD diagnosis and after 1 year of GFD the ALT levels remained steadily 3 times above the normal limit. In contrast, soon after steroid withdrawal a considerable flare-up of ALT levels was observed. This spike normalized after three months of a combined treatment of methylprednisolone and azathioprine. This normalization persisted after 18 months of immunosuppressive treatment which has been tapered down in the meantime. 


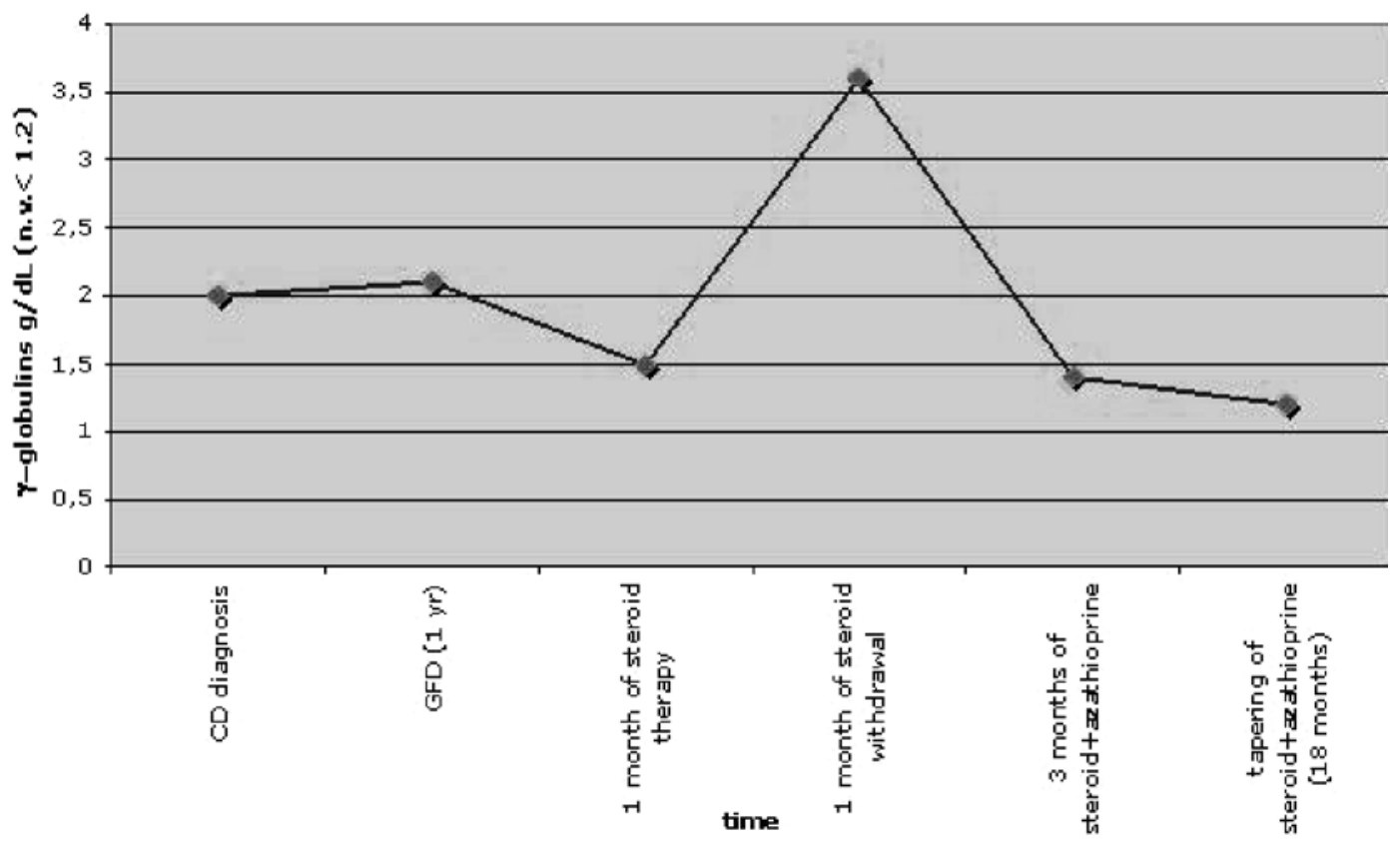

Fig. 3. Diagram showing $\gamma$-globulin levels over time. Likewise aminotransferases, at CD diagnosis and after 1 year of GFD the $\gamma$-globulin levels remained slightly above the normal limit and increased markedly upon steroid withdrawal. Again, following a combined treatment of methylprednisolone and azathioprine, $\gamma$-globulin levels normalized within three months. These values remained stable after 18 months of immunosuppressive treatment.

\section{References}

1 Alaedini A, Green PHR: Narrative review. Celiac disease: understanding a complex autoimmune disorder. Ann Int Med 2005;142:289-298.

2 Rostom A, Murray JA, Kagnoff MF: American Gastroenterological Association (AGA) Institute technical review on the diagnosis and management of celiac disease. Gastroenterology 2006;131:1981-2002.

3 Volta U: Pathogenesis and clinical significance of liver injury in celiac disease. Clin Rev Allergy Immunol 2009;36:62-70.

4 Volta U, De Franceschi L, Molinaro N, Cassani F, Muratori L, Lenzi M, Bianchi FB, Czaja AJ: Frequency and significance of anti-gliadin and anti-endomysial antibodies in autoimmune hepatitis. Dig Dis Sci 1998;43:2190-2195.

5 Villalta D, Girolami D, Bidoli E, Bizzarro N, Tampoia M, Liguori M, Pradella M, Tonutti E, Tozzoli R: High prevalence of celiac disease in autoimmune hepatitis detected by anti tissue transglutaminase antibodies. J Clin Lab Anal 2005;19:6-10.

6 Bardella MT, Fraquelli M, Quatrini M, Molteni N, Bianchi P, Conte D: Prevalence of hypertransaminasemia in adult celiac patients and effect of gluten-free diet. Hepatology 1995;22:833-836.

7 Volta U, De Franceschi L, Lari F, Molinaro N, Zoli M, Bianchi F: Celiac disease hidden by cryptogenic hypertransaminasemia. Lancet 1998;352:26-29.

8 Farre C, Esteve M, Curcoy A, Cabré E, Aranz E, Amat LL, Garcia-Tornel S: Hypertransaminasemia in pediatriac celiac disease patients and its prevalence as a diagnostic clue. Am J Gastroenterol 2002;97: 3176-3182.

$\$ 9$ Arslan N, Buyukgebitz B, Ozturk Y, Ozer E: The prevalence of liver function abnormalities in pediatric celiac disease patients and its relation with intestinal biopsy findings. Acta Gastroenterol Belg 2005;68:424-427.

10 Rubio-Tapia A, Murray JA: The liver in celiac disease. Hepatology 2007;46:1650-1658.

-11 Demir H, Yuce A, Caglar M, Kale G, Kocak N, Ozen H, Gürakan F, Saltik-Temizel IN: Cirrhosis in children with celiac disease. J Clin Gastroenterol 2005;39:630-633. 
12 Kaukinen K, Halme L, Collin P, Farkkila M, Maki M, Vehmanen H, Partanen J, Höckerstedt K: Coeliac disease in patients with severe liver disease: gluten free diet may reverse hepatic failure. Gastroenterology 2002;122:881-888.

13 Kingham JG, Parker DR: The association between primary biliary cirrhosis and celiac disease: a study of relative prevalences. Gut 1998;42:120-122.

-14 Volta U, Rodrigo L, Granito A, Petrolini N, Muratori P, Muratori L, Linares A, Veronesi L, Fuentes D, Zauli D, Bianchi FB: Coeliac disease in autoimmune cholestatic liver disorders. Am J Gastroenterol 2002;27:2609-2613.

-15 Czaja AJ, Morshed SA, Parveen S, Nishioka M: Antibodies to single-stranded and double-stranded DNA in antinuclear antibody-positive type 1-autoimmune hepatitis. Hepatology 1997;26:567-572. 